\title{
Correction to: From a Dog's Breakfast to a King's Table: Branding and Marketing a Major Research University
}

\author{
Julia Cummings and Ken McConnellogue
}

\section{Correction to:}

Chapter 14 in: S. M. Zavattaro (ed.), Public Branding and Marketing, https://doi.org/10.1007/978-3-030-70505-3_14

The text "We think this should this be "propel" since it's about mission + our people. That's the way we had it in the original draft" and "We submitted some short bios to Staci. Will those go after the conclusion?" has been accidently included in the chapter. This has now been corrected throughout the chapter.

The updated online version of this chapter can be found at https://doi.org/10.1007/978-3-030-70505-3_14 